\title{
Changes in expression of steroid receptors, their downstream target genes and their associated co-regulators during the sequential acquisition of tamoxifen resistance in vitro
}

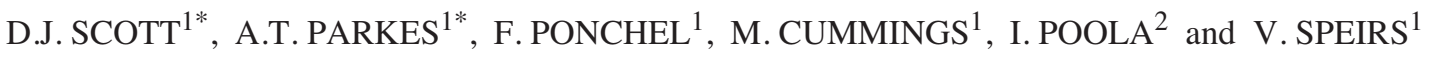 \\ ${ }^{1}$ Leeds Institute of Molecular Medicine, University of Leeds, Leeds LS9 7TF, UK; ${ }^{2}$ Department of Biochemistry \\ and Molecular Biology, Howard University College of Medicine, Washington, DC 20059, USA
}

Received January 29, 2007; Accepted February 28, 2007

\begin{abstract}
Tamoxifen resistance (TAMr) in breast cancer is a serious clinical dilemma, with no satisfactory explanation. We hypothesised that changes in the expression of steroid hormone receptors (ER $\alpha, E R ß)$, their downstream target genes (PR, pS2) and their associated co-regulators (AIB-1, SRC-1, SRA, NCoR-1, SMRT and REA) could be related to the acquisition of TAMr. To test this hypothesis, we developed in vitro TAMr cell line models by continuous exposure of MCF-7 cells to 4-hydroxytamoxifen (4-HT) over 12 (MCF-7 $\left.{ }^{\mathrm{MMU} 1}\right)$ and 21 (MCF-7 ${ }^{\mathrm{MMU}}$ ) months, respectively and examined the expression of the above by Western blotting and immunohistochemistry. In addition, we further examined the changes in global gene expression in TAMr cells in comparison with TAM-sensitive cells by microarray analysis. We report here that acquisition of TAMr is associated with changes in the expression of $\mathrm{PR}, \mathrm{pS} 2$ and several co-activators, but not ERs. In addition, genes associated with cell cycle, cell adhesion and extracellular matrix, were up-regulated while those associated with apoptosis or growth factors/hormones were down-regulated. Based on our results, it appears that increased co-activator expression, in concert with alterations in genes associated with controlling cell proliferation and survival contribute to TAMr in breast cancer.
\end{abstract}

\section{Introduction}

Tamoxifen (TAM) has been the primary line of therapy for ER $\alpha$-positive breast cancer patients for nearly three decades and continues to be the choice of therapy for pre-menopausal

Correspondence to: Dr V. Speirs, Leeds Institute of Molecular Medicine, Wellcome Trust Brenner Building, St. James' University Hospital, Leeds LS9 7TF, UK

E-mail:v.speirs@leeds.ac.uk

${ }^{*}$ Contributed equally

Key words: breast cancer, tamoxifen resistance, microarray patients $(1,2)$. Clinical studies have shown that about $70 \%$ of patients initially respond to this therapy but eventually acquire resistance (3) and the development of TAM resistance (TAMr) is a major clinical problem for long-term management of breast cancer (4).

The mechanism of action of TAM has been extensively investigated. It is now established that anti-tumour activity of TAM is mediated by binding to estrogen receptors (ER), ER $\alpha$ and $E R ß$. Although the requirement of $E R \alpha$ in the response to TAM is undebated, the role of ERß remains controversial (5). The current thinking views it as a good prognostic marker (6).

In recent years it has become apparent that in addition to receptor binding, ER-signalling involves a complex array of co-regulatory proteins that function to enhance (co-activators) or repress (co-repressors) gene transcription (7-9). Alterations in levels of co-regulators have been implicated in breast tumourigenesis and TAMr. Overexpression of SRC-1, AIB-1, and SRA have been reported in primary breast tumours (10-12). Elevated levels of SRC-1 and AIB-1 have been associated with decreased response to endocrine therapy and poorer clinical outcome, which may ultimately result in TAMr through enhancing its agonist behaviour (13-15). TAMr tumours often have reduced levels of NCoR-1 (16-18). A role for corepressors in TAM action has been supported by evidence that in the presence of TAM a stronger association with ER $\alpha$ occurs $(16,19)$.

The aim of this work was to develop and characterise an in vitro model of TAMr and identify molecular changes associated with this phenomenon. Using immunohistochemistry and quantitative real-time PCR we investigated the expression of $\mathrm{ER} \alpha, \mathrm{ER} \beta, \mathrm{PR}$ and $\mathrm{pS} 2$ in association with a small subset of 3 co-activators and 3 co-repressors in TAM sensitive MCF-7 cells and in our in-house model of acquired TAMr. Finally we used microarray analysis to explore changes in global gene expression associated with the acquisition of resistance.

\section{Materials and methods}

Development of an in vitro model of TAMr. MCF-7 cells were cultured in phenol-red free RPMI-1640 containing L-glutamine (both Invitrogen, Paisley, UK) supplemented with 5\% charcoal-stripped steroid-depleted FCS (Harlan SeraLab, 
Table I. Real-time PCR primer sequences.

\begin{tabular}{llll}
\hline Gene & Accession no. & \multicolumn{1}{c}{ Forward primer } & \multicolumn{1}{c}{ Reverse primer } \\
\hline$E R \alpha$ & M12674 & dAGAGGGCATGGTGGAGATCTT & dCAAACTCCTCTCCCTGCAGATT \\
$E R \beta$ & AB006593 & dTGGTCCATCGCCAGTTATCA & dAGGTGTGTTCTAGCGATCYYGCTT \\
$P R$ & M15716 & dGAACAGCGGATGAAAGAATCATC & dTTGAAGCTTGACAAACTCCTGTC \\
$p S 2$ & X00474 & dATCGACGTCCCTCCAGAAGAG & dCTCTGGGACTAATCACCGTGCT \\
$S R C-1$ & U40396 & dAACGTCAGCGGGAACTGTACA & dTGCCTCATAAGCATGGCTCTT \\
$A I B-1$ & AF012108 & dTGGGAAGACCAGGAGGAGATT & dCTATTAGACCGAAGAGGCAATGTG \\
$S R A$ & AF092038 & dCCGGTGGGACGCAGC & dACTCCTACCATCCACTGACTGACC \\
$N C o R-1$ & NM006311 & dTCAGCCAGAGGTTGTTAAGGC & dTCGATAGTGATGTAATGGTCCTTCATA \\
$S M R T$ & XM006737 & dTTCACACATCGTTGCCGC & dAAAATATACCCTGTAAACCAACACATC \\
$R E A$ & AF150962 & dAGGGTAAGAAATGAGCCTAGTCACC & dGGTAGGGCTGTGCTGGACC \\
$R P L P 0$ & M17885 & dGCTCAACATCTCCCCCTTCTC & dGATATCAAGCACTTCAGGGTTGTAGA \\
\hline
\end{tabular}

Loughborough), $100 \mathrm{U} / \mathrm{ml}$ penicillin and $100 \mathrm{U} / \mathrm{ml}$ streptomycin and $100 \mathrm{nM}$ 4-hydroxytamoxifen (4-HT; Sigma, Poole), an active metabolite of TAM (20-22). We used 4-HT for 3 reasons: a) its binding affinity for $\mathrm{ER} \alpha$ is higher than that of TAM $(20,22)$, b) MCF-7 cells have limited capacity to metabolise TAM into its active metabolites and c) so we could directly relate our data to the results of other groups using similar models $(22,23)$. Two separate lines were developed. MCF-7 ${ }^{\text {MMU1 }}$ was grown for 12 months in 4-HT with periodic cell characterisation. MCF-7 $7^{\mathrm{MMU} 2}$ was cultured for 21 months in 4-HT after which this was removed and cells cultured for further 12 months. Parental MCF-7 cells (sensitive to 4-HT) were cultured in the same growth media as the MCF-7 ${ }^{\mathrm{MMU} 1}$ or MCF-7 ${ }^{\mathrm{MMU} 2}$ cells, but with ethanol vehicle only. In some cases, MCF-7 ${ }^{\mathrm{MMU} 2}$ early (E) and late (L) were also studied which relate to $\mathrm{MCF}-7^{\mathrm{MMU} 2}$ cells grown in the absence of 4-HT for 13 (E) or 56 (L) passages. Bimonthly checks for mycoplasma spp. were negative.

Cell cycle analysis. Cells were seeded in 6-well plates $\left(4 \times 10^{4}\right.$ cells/well) and allowed to reach log phase. Thereafter, cells were treated with either $1 \mathrm{nM}$ E2 or $100 \mathrm{nM} 4-\mathrm{HT}$ for $72 \mathrm{~h}$ prior to overnight fixation with $70 \%$ ice-cold ethanol at $-20^{\circ} \mathrm{C}$. Fixed cells were then incubated with $50 \mu \mathrm{g} / \mathrm{ml}$ propidium iodide and $5 \mathrm{U} / \mathrm{ml}$ RNase (Sigma-Aldrich). Following overnight incubation at $4^{\circ} \mathrm{C}$ samples were analysed on a Coulter Epics XL flow cytometer (Beckman Coulter, High Wycombe) using the FL-3 photomultiplier to measure DNA content. Cell cycle distribution was quantified using multicycle software (Phoenix Flow Systems, San Diego, CA).

Immunohistochemistry. Cells were grown to log phase on glass slides (VWR International) and fixed in methanol:acetic (1:1). Blocking using $100 \mu 1$ of normal rabbit serum (1:20) (DakoCytomation) was performed for $30 \mathrm{~min}$ at room temperature. Anti-ER $\alpha$ and PR antibodies (both DakoCytomation) were applied at 1:100 dilution and incubated at room temperature for $60 \mathrm{~min}$. Anti-ERß antibody (1:200; AbCam) was incubated overnight at $4^{\circ} \mathrm{C}$. Negative controls included substitution of primary antibody with rabbit serum. Three washes [TBS ( $\mathrm{pH} 7.6$ ) for $5 \mathrm{~min}$ ] preceded 30-min incubation in biotinylated secondary IgG (rabbit anti-mouse; 1:200; DakoCytomation). Slides were again washed before detection using streptavidin peroxidase (DakoCytomation), according to the manufacturer's recommendations. The final colour reaction was achieved using 3,3'-diaminobenzidine tetrahydrochloride (DAB) (Sigma) for $10 \mathrm{~min}$ and lightly counterstained with Mayer's haematoxylin. Slides were then dehydrated and taken through graded alcohols to xylene and finally mounted. Slides were viewed under light microscopy (Nikon Eclipse E1000) and analysed using Lucia software (version 4.51).

Western blotting. Western blotting was conducted as previously described using the same primary antibodies under identical conditions $(24,25)$. Full-length ERß purified human recombinant protein standard (PanVera) was including in some experiments.

Real-time polymerase chain reaction. Using standard procedures (Qiagen), total RNA (10 $\mu \mathrm{l})$ was reverse-transcribed in a final volume of $20 \mu \mathrm{l}$ containing $1.5 \mu \mathrm{l}$ of oligo(dT) $)_{12-18}$ primer $(0.5 \mu \mathrm{g} / \mu \mathrm{l}), 2 \mu \mathrm{l}$ of $100 \mathrm{mM}$ DTT, $4 \mu 15 \mathrm{X}$ first strand buffer (25 mM Tris- $\mathrm{HCl} \mathrm{pH} 8.3,37.5 \mathrm{mM} \mathrm{KCl}, 1.5 \mathrm{mM}$ $\mathrm{MgCl}_{2}$ ), $1 \mu \mathrm{l}$ dNTPs (10 mM each dNTP), $20 \mathrm{U}$ of RNase inhibitor (Roche Diagnostics, Mannheim, Germany) and $200 \mathrm{U}$ of Superscript II reverse transcriptase (all Invitrogen). Realtime quantitative PCR was performed using the ABI PRISM 7700 Sequence Detection System and the SYBR Green PCR Core Reagents kit according to the manufacturer's instructions (Perkin-Elmer Applied Biosystems). Primers were designed using the Primer Express program, which selected theoretically optimised primers for this system. Primer sequences are shown in Table I. An initial incubation of $50^{\circ} \mathrm{C}$ for $2 \mathrm{~min}$ was followed by denaturing at $95^{\circ} \mathrm{C}$ for $10 \mathrm{~min}$ and then 40 cycles at $95^{\circ} \mathrm{C}$ for $15 \mathrm{sec}$ and $60^{\circ} \mathrm{C}$ for $1 \mathrm{~min}$. PCR products were detected by bound SYBR Green double-stranded DNA fluorescence (26). Target gene expression was expressed relative to the housekeeping gene $R P L P O$. All experiments were performed in triplicate. 
Table II. Effects of E2 and 4-HT on cell cycle distribution of MCF-7, MCF-7 ${ }^{\mathrm{MMU} 1}$ and MCF-7MMU2.

\begin{tabular}{|c|c|c|c|c|}
\hline Cell line & Treatment & $\%$ G1 & $\% \mathrm{~S}$ & $\% \mathrm{G} 2$ \\
\hline \multirow[t]{3}{*}{ MCF-7 } & Con & $64.05 \pm 1.38$ & $22.53 \pm 1.80$ & $13.43 \pm 0.82$ \\
\hline & E2 & $47.6 \pm 0.50$ & $40.70 \pm 0.52^{\mathrm{a}}$ & $12.10 \pm 0.50$ \\
\hline & 4-HT & $72.2 \pm 0.28$ & $13.40 \pm 0.42^{\mathrm{a}}$ & $14.45 \pm 0.78$ \\
\hline \multicolumn{5}{|l|}{ MCF-7MMU1 } \\
\hline \multirow[t]{3}{*}{ M4 } & Con & $61.25 \pm 1.20$ & $17.10 \pm 0.28$ & $21.70 \pm 0.85$ \\
\hline & E2 & $58.8 \pm 0.14$ & $20.55 \pm 0.49$ & $20.60 \pm 0.42$ \\
\hline & 4-HT & $60.65 \pm 0.49$ & $18.95 \pm 0.42$ & $20.50 \pm 0.78$ \\
\hline \multirow[t]{3}{*}{ M7 } & Con & $52.05 \pm 0.78$ & $23.10 \pm 0.28$ & $24.85 \pm 1.06$ \\
\hline & E2 & $54.20 \pm 3.54$ & $25.55 \pm 1.48$ & $20.25 \pm 2.05$ \\
\hline & 4-HT & $55.50 \pm 0.14$ & $25.15 \pm 0.35$ & $19.35 \pm 0.49$ \\
\hline \multirow[t]{3}{*}{ M9 } & Con & $53.90 \pm 2.69$ & $20.25 \pm 0.78$ & $25.85 \pm 1.91$ \\
\hline & $\mathrm{E} 2$ & $50.80 \pm 0.42$ & $18.90 \pm 0.99$ & $30.30 \pm 0.57$ \\
\hline & 4-HT & $51.25 \pm 1.77$ & $20.30 \pm 0.99$ & $29.75 \pm 1.06$ \\
\hline \multirow[t]{3}{*}{ M12 } & Con & $48.60 \pm 0.85$ & $22.10 \pm 1.70$ & $29.15 \pm 0.92$ \\
\hline & E2 & $48.10 \pm 0.42$ & $20.95 \pm 0.07$ & $30.95 \pm 0.49$ \\
\hline & 4-HT & $50.10 \pm 0.71$ & $21.20 \pm 0.85$ & $28.65 \pm 1.49$ \\
\hline \multirow[t]{3}{*}{ MCF-7MMU2 } & Con & $53.75 \pm 1.48$ & $26.90 \pm 0.71$ & $19.30 \pm 0.71$ \\
\hline & $\mathrm{E} 2$ & $49.00 \pm 0.57$ & $28.65 \pm 0.92$ & $22.40 \pm 0.42$ \\
\hline & 4-HT & $56.50 \pm 0.71$ & $26.50 \pm 0.28$ & $17.00 \pm 0.99$ \\
\hline
\end{tabular}

Results are shown as percentage of cells present in each phase of the cells cycle and are the mean \pm SD of 3 independent experiments. For $\mathrm{MCF}^{\mathrm{MMU}}$, response to hormone was determined after 4, 7, 9 and 12 months (M) in the continuous presence of 4-HT. Significant differences in proliferation in response to E2 or 4-HT were only seen in the parental MCF-7 cells, confirming the onset of resistance. ${ }^{\mathrm{a}} \mathrm{p}<0.05$ versus control.

Microarray analysis. Total RNA was extracted from MCF$7^{\mathrm{MMU} 1}$ cells after 12 months in the continuous presence of $100 \mathrm{nM}$ 4-HT and from parental MCF-7 controls using the Qiagen RNeasy Midi total RNA isolation kits (Qiagen, Valencia, CA) followed by further purification using two sequential Qiagen RNeasy Mini total RNA isolation columns according to manufacturer's protocol. RNA integrity was verified by amplification of the constitutively expressed gene, glyceraldehyde-3 phosphate dehydrogenase (GAPDH), following cDNA synthesis. Purified RNA samples were processed for oligonucleotide microarray analysis according to standard Affymetrix protocols. Arrays were washed with a non-stringent buffer (20X SSPE, 10\% Tween-20) and a stringent buffer (12X MES, $5 \mathrm{M} \mathrm{NaCl}, 10 \%$ Tween-20) and scanned (Agilent GeneArray Scanner). Fluorescence intensities were quantified, correlated for background noise and normalized to a standard expression level, and then exported to GeneSpring (Silicon Genetics). Affymetrix Microarray Suite software calculated a percentage positive of present genes. Genes showing $\geq 3$-fold up- or down-regulation relative to vehicle control were considered significant. Array experiments were repeated twice and for each run cells from three different flasks were pooled to prepare RNA. Array experiments were carried out at The Genomics Core Facility, The George Washington University Medical School,
Washington, DC. Genes were assigned functional categories by mining several databases including PubMed (http:// www.ncbi.nlm.nih.gov) and associated resources therein or GeneCards (http://www.bioinformatics.weizmann.ac.il/cards).

Statistical analyses of data. Student's unpaired t-tests were used to determine statistical significance for flow cytometry data. Mann-Whitney U tests were used to determine statistical significance for real-time RT-PCR data. A p $<0.05$ was considered significant.

\section{Results}

Cells lost sensitivity to E2 and 4-HT after maintaining for 4 months in the presence of 4-HT. Two models of TAMr were developed and designated MCF-7 ${ }^{\mathrm{MMU} 1}$ and MCF-7MMU2. DNA content analysis was performed to determine the precise effects of E2 and 4-HT treatment on cell cycle distribution using flow cytometry (Table II). Compared to parental cells which were significantly growth inhibited by 4-HT, MCF-7 ${ }^{\text {MMU1 }}$ became refractory to its inhibitory properties by month 4 . MCF-7MMU1 cells were also less responsive to the stimulatory effects of E2 as resistance developed. Following long-term culture in 4-HT, MCF-7 ${ }^{\mathrm{MMU} 2}$ was developed. These cells retained their resistant phenotype following removal of 4-HT and growth 
was similarly unaffected by adding either E2 or 4-HT to the culture medium (data not shown).

ER $\alpha$ and ERß protein expression was unaltered but $P R$ was markedly reduced during acquisition of TAMr. To determine whether TAMr was associated with altered ER expression, Western blot and immunocytochemical analyses for ER $\alpha$ and ERß was performed. ER $\alpha$ was the predominant ER in wtMCF-7 cells. In MCF-7MMU1 cells, expression was slightly reduced while in $\mathrm{MCF}-7^{\mathrm{MMU} 2}$ cells, levels were comparable to wtMCF-7. ERß expression was validated using 2 different antibodies and was by far the lowest protein expressed in the cell line model. Using the 14C8 antibody, ERß was undetectable, even when $30 \mu \mathrm{g}$ of protein lysate was loaded however full-length ERß recombinant protein, used as a positive control could be detected. Weak ERß expression was seen in both wtMCF-7 and the TAMr sublines with the 8D5 antibody, which also recognised recombinant full-length ERß. Using the 8D5 antibody, ERß was more strongly expressed in wtMCF-7 compared to the 4-HT-treated cells. PR-A was the predominant PR isoform in wtMCF-7 and 4-HT treated cells. PR expression was greatly reduced following the onset of TAMr, as shown by reduced band intensity from months 6-12, and remained low in TAMr cells compared to wtMCF-7. Immunocytochemical analysis of the same cells mirrored Western blot data (Fig. 1f). Predominantly nuclear ER $\alpha$ immunoreactivity was observed whereas ERß immunoreactivity was weaker and more diffuse with patchy granular cytoplasmic staining as well as nuclear immunoreactivity (Fig. 1f). The estrogen-regulated PR was abundantly expressed in wtMCF-7 cells but was markedly reduced in the TAMr series (Fig. 1f).

Co-activator mRNA levels were increased but the co-repressors were unchanged during acquisition of TAMr. ER $\alpha$ expression was reduced in the early months of MCF-7 ${ }^{\mathrm{MMU}}$ development but levels started to rise around month 9 and exceeded basal levels by month 12 , while in MCF-7 ${ }^{\mathrm{MMU} 1}$ levels remained similar to wtMCF-7 (Fig. 2a). As observed at the protein level, $E R \alpha$ expression exceeded $E R \beta$ and while levels of $E R \beta$ were low overall, these increased in the early stages of MCF-7MMU1 development (Fig. 2b). $P R$ expression declined rapidly then reached plateau with low levels also seen in MCF-7 ${ }^{\text {MMU2 }}$ (Fig. 2c), while $p S 2$ levels were high in MCF-7MMU1 but were markedly reduced in MCF-7MMU2 (Fig. 2d). AIB-1 was the most highly expressed co-activator in all cells and in MCF-7 $7^{\mathrm{MMU} 2}$ (E) remained above twice the level observed in wtMCF-7 while in $\mathrm{MCF}-7^{\mathrm{MMU} 2}$ (L) cells, expression was similar to wtMCF-7 (Fig. 3a). Expression of $S R C-1$ mirrored that of AIB-1 (Fig. 3b). SRA showed a linear increase in expression in the MCF-7 ${ }^{\mathrm{MMU} 1}$ series until month 6 , after which the levels of expression decreased and appeared to plateau. No difference in expression was observed in MCF-7 ${ }^{\mathrm{MMU} 2}$ cells, where levels were comparable to wtMCF-7 (Fig. 3c). Similar expression profiles were seen with $N C o R-1$ and SMRT (Fig. 3d and e, respectively) throughout the MCF-7 ${ }^{\mathrm{MMU} 1}$ series however $S M R T$ expression was reduced in MCF-7 ${ }^{\mathrm{MMU} 2}$ compared to wtMCF-7 and MCF-7MMU1 cells. REA was the most highly expressed corepressor and in general remained constant as cells developed TAMr (Fig. 3f).
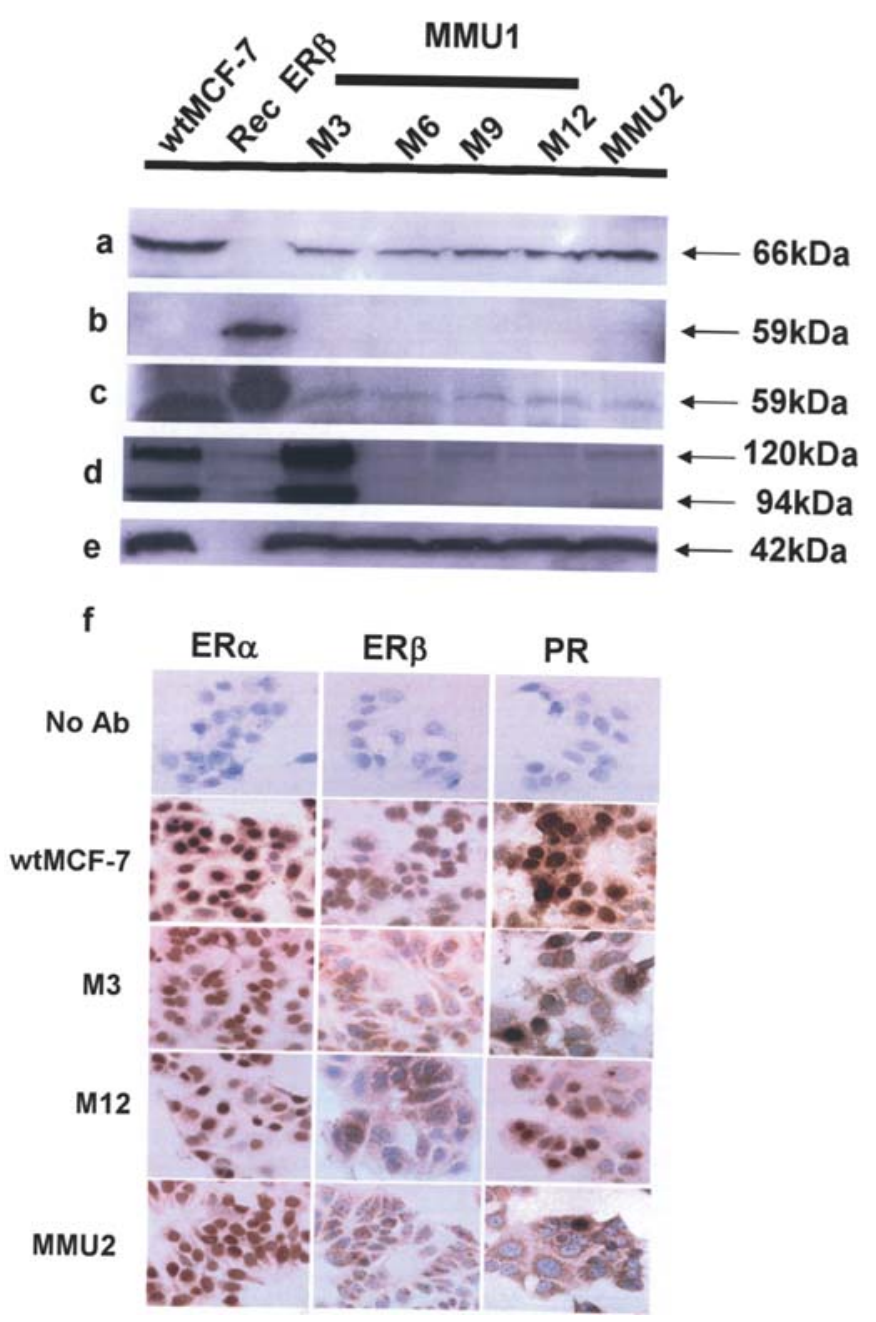

Figure 1. Western blot analysis of wtMCF-7, MCF-7 ${ }^{\mathrm{MMU} 1}$ (months 3, 6, 9 and 12) and MCF-7 $7^{\mathrm{MMU} 2}$ showed $\mathrm{ER} \alpha$ (a) was retained as TAMr developed. ERß was only detected in both wtMCF-7 and TAMr sublines using the 8D5 antibody (c), but not with an alternative ERß antibody, 14C8 (b). PR-A and -B were expressed in wtMCF-7 and at a reduced level in the TAMr sublines from 3 months (M3) onwards (d). Probing with $\beta$-actin showed equivalent loading (e). Immunocytochemical data are presented in (f) and complement Western blot data. Strong uniform nuclear ER $\alpha$ immunoreactivity was observed and unaltered as resistance to TAM developed after 3 (M3) of 12 (M12) months exposure to TAM or 21 months (MMU2). ERß staining was less intense and showed a granular cytoplasmic pattern of staining, consistent in all samples. PR staining was strongly nuclear in wtMCF-7 and demonstrated a non-uniform pattern of expression, however, expression was reduced as TAMr developed. Original magnification $\mathrm{x} 200$.

Global gene expression by microarray analysis of tamoxifen sensitive and resistant MCF-7 cells revealed up-regulation of proliferation promoting genes and down-regulation of apoptosis inducers. Genes differentially regulated $>3$-fold between MCF-7MMU1 and wtMCF-7 cells were considered significant. Using this criterion, 131 genes were up-regulated and 156 genes were down-regulated in MCF-7MMU1 cells relative to wtMCF-7 cells. Good concordance was demonstrated between repeat arrays. Differentially regulated genes were then categorised according to function by subdividing into 12 functional categories plus unknowns. The proportion of genes in each category were broadly similar, although genes associated with cell cycle, cell adhesion or extracellular matrix 

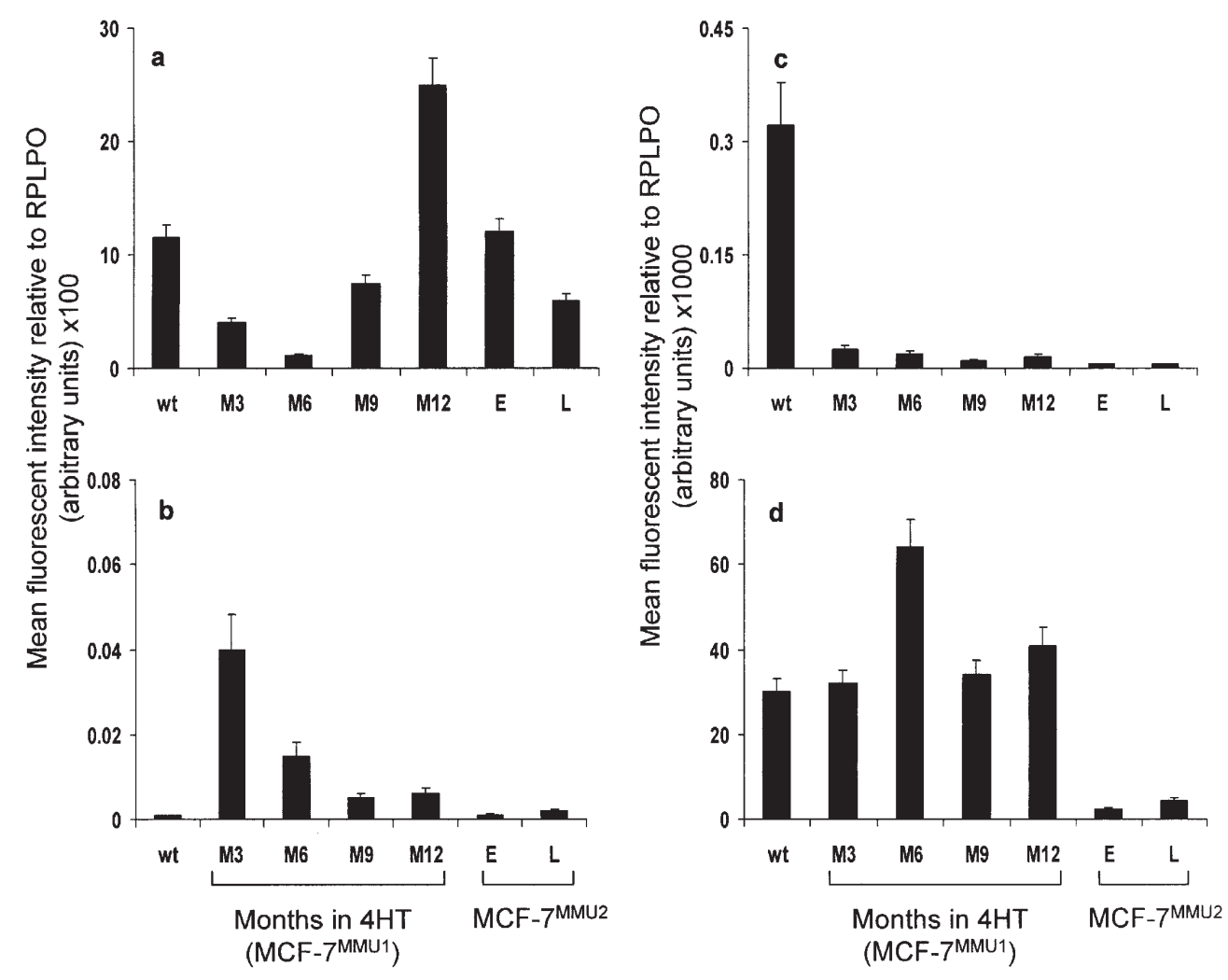

Figure 2. Real-time RT-PCR analysis of hormone receptor expression during development of 4-HT resistance. (a), ER $\alpha$; (b), ERß; (c), PR; (d), pS2. Expression levels were calculated relative to the housekeeping gene, $R P L P 0$. Data represent mean $\pm \mathrm{SEM} .{ }^{*} \mathrm{p}<0.05$.

were generally up-regulated while those associated with apoptosis or encoding growth factors or hormones were down-regulated in MCF-7 ${ }^{\mathrm{MMU} 1}$ cells compared with wtMCF-7 cells (Fig. 4). A selection of estrogen-regulated and cancerassociated genes together with those whose expression was mostly highly altered following TAMr are shown in Table III. Ten estrogen-regulated genes which were up-regulated included: GREB1, AREG, CXCL12, CA12, WISP2, EP3, LIV-1 and IGFBP5. The cancer-associated genes which were most highly up-regulated included: $S 100 P$, SOX9, TIMP3, CEACAM6, SGP28, Caveolin-1 and AIB-1. The most significantly up-regulated gene was $H M G C S 2$, which showed a 79-fold increase in MCF-7MMU1 cells and the most downregulated gene was NPYRI (68-fold decrease in MCF-7 ${ }^{\mathrm{MMU} 1}$ cells).

\section{Discussion}

We have developed and characterised 2 different TAMr cell lines derived from MCF-7. These are different from other published models of TAMr in that we mirrored changes in gene and protein expression as TAMr evolved, rather than just studying the end point. Both MCF-7 ${ }^{\mathrm{MMU}}$ and $\mathrm{MCF}-7^{\mathrm{MMU} 2}$ cells were less sensitive to the stimulatory effects of E2 and refractory to the inhibitory effects $4-\mathrm{HT}$. They retained levels and localisation of ER $\alpha$ and ERß that were comparable to wtMCF-7 content by Western blotting and immunohistochemistry. A reduction in PR was consistent with the development of TAMr. These general observations are consistent with other published TAMr models (27-32).
Table III. Some examples of genes up- and down-regulated in $\mathrm{MCF}-7^{\mathrm{MMU} 1}$ cells relative to wtMCF-7 cells following microarray analysis.

\begin{tabular}{llcc}
\hline Category & \multicolumn{1}{c}{ Gene } & Fold change & Direction \\
\hline Most altered & HMGCS2 & 79 & $\mathrm{Up}$ \\
& NPYR1 & 68 & Down \\
Cancer-related & SIOOP & 46 & $\mathrm{Up}$ \\
& SOX9 & 30 & $\mathrm{Up}$ \\
& TIMP3 & 22 & $\mathrm{Up}$ \\
& CEACAM6 & 20 & $\mathrm{Up}$ \\
& SGP28 & 14 & $\mathrm{Up}$ \\
& Caveolin 1 & 12 & $\mathrm{Up}$ \\
& AIB1 & 3 & $\mathrm{Up}$ \\
& & & \\
E2-responsive & GRE1 & 15 & Down \\
& WISP1 & 10 & Down \\
& AREG & 9 & Down \\
& CAI2 & 9 & Down \\
CXCL12/SDF-1 & 8 & Down \\
PR & 6 & Down \\
EGR3 & 4 & Down \\
EP3 & 4 & Down \\
IGFBP5 & 4 - 1 & 4 & Down \\
& & & Down \\
\hline & & 4 &
\end{tabular}



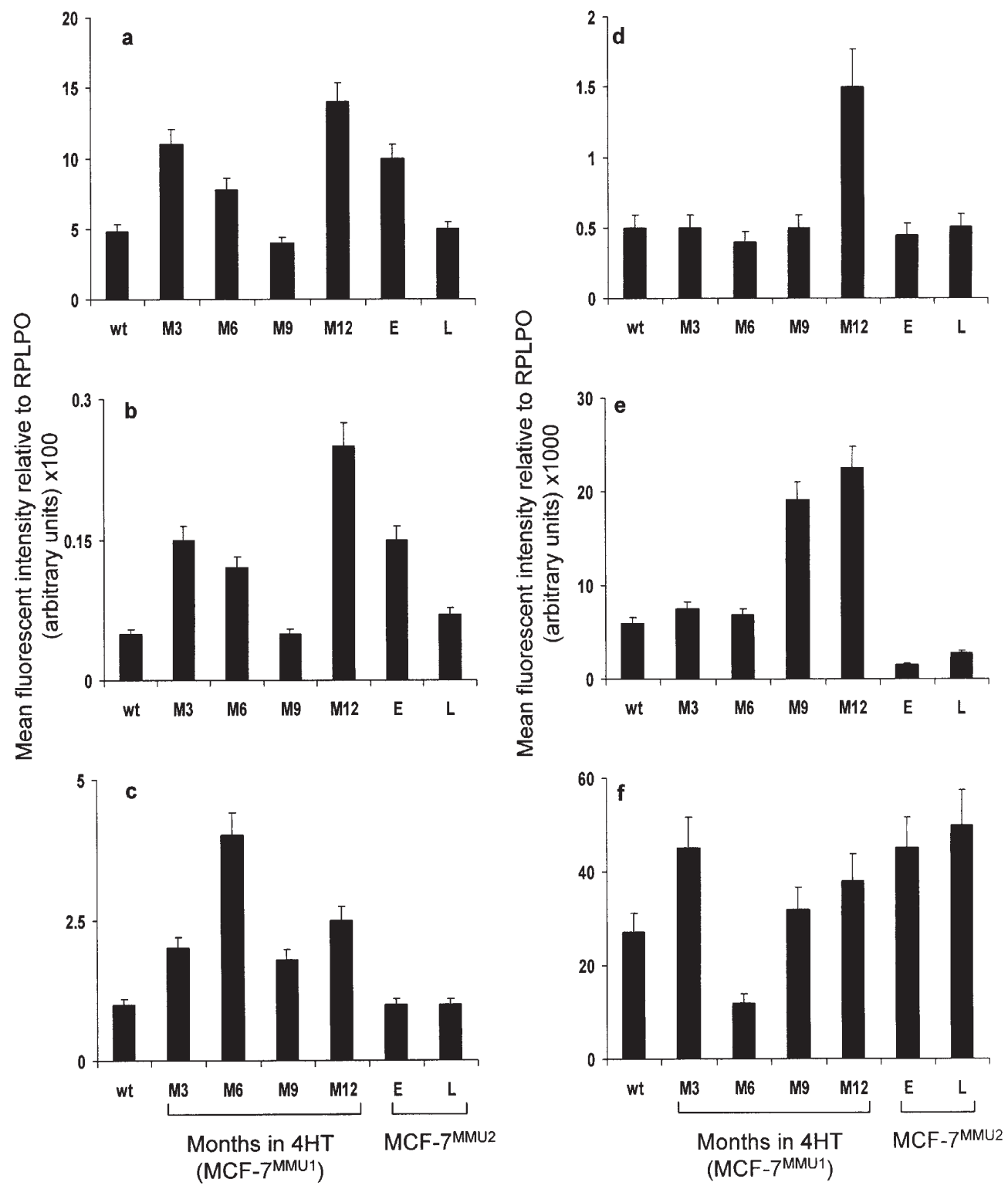

Figure 3. Real-time RT-PCR analysis of the ER co-regulators AIB-1 (a), SRC-1 (b), SRA (c), NCoR-1 (d), SMRT (e) and REA (f) during development of 4-HT resistance. Expression levels were calculated relative to the housekeeping gene, RPLPO. Data represent mean $\pm \mathrm{SEM}$. ${ }^{*} \mathrm{p}<0.05$.

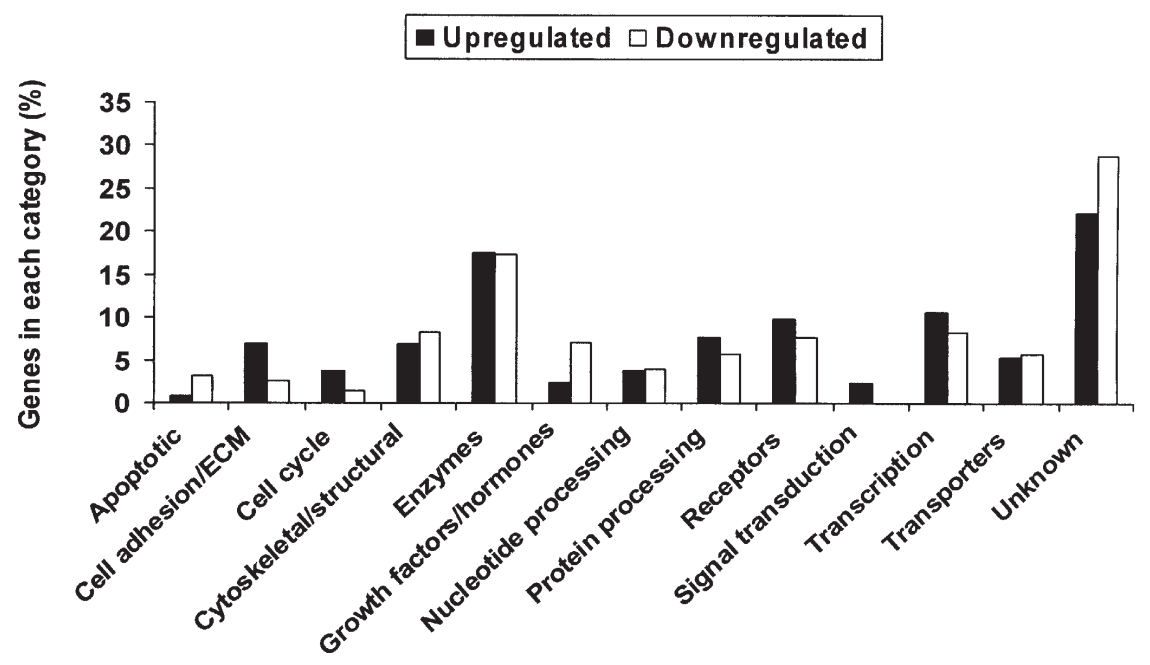

Figure 4. Functional categories of genes up- and down-regulated between MCF-7MMU1 and wtMCF-7 cells by microarray. Differentially regulated genes were assigned to 1 of 12 functional categories or to an unknown category by mining several databases (Materials and methods). Data are expressed as a percentage of the total number of up- or down-regulated genes. 
$E R \alpha$ expression exceeded that of $E R \beta$ in accord with other studies (32-36). This has also proven to be the case in a xenograft model of anti-estrogen resistance and in clinical breast cancer $(37,38)$. Although $E R \beta$ expression was low, we did see elevated expression at months 3 and 6, which coincided with the initial adaptation of resistance. As ERß is now generally regarded as good prognostic marker (6), this could suggest that this is an adaptive response to the onset of the TAMr phenotype. Interestingly, ERß staining was not exclusively nuclear and supports the finding of cytoplasmic ERß by other groups $(24,39,40)$. This has been suggested to be due to cross-reactivity with cytoplasmic proteins (41). However, in our hands cytoplasmic staining was negated by pre-absorption of antibody with recombinant peptide (24), suggesting it is real, although its function remains unresolved but deserves further investigation.

Basal expression of $p S 2$ was only reduced in MCF-7 ${ }^{\mathrm{MMU} 2}$. Although a reduction in $p S 2$ expression has been reported in some studies, this did not reflect loss of ER activity since response to E2-stimulation was also observed $(29,36,42)$. Both unaltered $(28,29,36)$ and reduced $(31,42)$ levels of pS2 have been described in models of TAMr. These observations suggest that different selective mechanisms may operate during the differential acquisition of TAMr, particularly as we only observed loss of $p S 2$ expression in $\mathrm{MCF}-7^{\mathrm{MMU} 2}$ and not in MCF-7MMU1 cells, which were developed independently.

$A I B-1$ was the most highly expressed co-activator in our TAMr model and was also similarly identified by microarray analysis. Overexpression of AIB-1 has been reported in breast cancer irrespective of ER $\alpha$ expression $(10,12,43)$. AIB-1 expression correlated with poorer prognosis in breast cancer and reduced response to hormonal therapy (15). Elevated levels of $A I B-1$ have been reported in other breast cancer cell studies $(32,33,44,45)$. Elevated levels in our in vitro TAMr model strengthen the involvement of AIB-1 in breast carcinogenesis and its further elevation in TAMr suggests it may be contributory to this phenomenon.

$S R C-1$ was elevated in both $\mathrm{MCF}-7^{\mathrm{MMU} 1}$ and $\mathrm{MCF}-7^{\mathrm{MmU}} 2$ relative to wtMCF-7. Shang and Brown (46) concluded that high levels of SRC-1 were sufficient to support the agonist activity of TAM and showed increased expression of ERregulated genes by TAM stimulation in SRC-1-transfected MCF-7 cells, but not AIB-1-transfected cells. This is in agreement with Smith et al (13) who demonstrated that overexpression of SRC-1 was associated with the enhanced agonist activity of TAM, and upheld by Xu et al (14), who used SRC-1 knockout mice to demonstrate the potential involvement of SRC-1 in TAM resistance. Fleming et al (47) associated SRC-1 expression with poor response to endocrine therapy in a series of breast tumours. Therefore, increased levels of $S R C-1$ in our model would support a less favourable antagonist effect of TAM on growth of MCF-7 cells. An interesting observation was the reduction of $A I B-1$ and $S R C-1$ levels in the MCF-7 ${ }^{\mathrm{MMU} 2}$ cells which had been devoid of 4-HT for approximately 12 months. The results may suggest that over time the expression of co-factors involved in driving TAMr may revert back to wild-type levels. Therefore it would be interesting to re-evaluate these levels in relation to the length of time following TAM removal and hormone response.
SRA is unable to directly bind ER, and is more likely to act as an adaptor molecule, bridging the association with other co-activators (48). However it is expressed in breast cancer where it is believed to modulate ER activity (49). In our study, expression was not significantly altered in MCF-7MMU1 and $\mathrm{MCF}-7^{\mathrm{MMU}}$, suggesting it has little role in development of TAMr.

REA was the most significantly expressed co-repressor and in general its expression was higher in both the MCF-7 $7^{\mathrm{MMU}}$ and MCF-7 ${ }^{\mathrm{MMU}}$ series than wtMCF-7. Higher expression of REA may reflect competition between SRC-1 and REA for $\mathrm{ER} \alpha$ and ERß $(19,50)$. Since a consistent increase in SRC-1 was seen in the MCF-7 $7^{\mathrm{MMU} 1}$ and MCF-7MMU2 cells it would seem appropriate that REA was also elevated in response. This uniform pattern suggests that elevated levels of REA may be a common feature of the TAMr phenotype. However, since REA requires an intact $\mathrm{F}$ region, within the AF-2 domain (51) it is unlikely that altered expression would induce TAMr if AF-2 activity is compromised. Recent data from animal models have shown that REA is required for maintenance of ER activity and normal mammary gland development (52).

NCoR-1 and SMRT are not specific for ER activity, but can repress ER transcription in the presence of anti-estrogens $(53,54)$. Decreased NCoR-1 protein expression in a mouse model of TAMr, reduced expression in association with shorter relapse-free survival in breast cancer patients and higher levels of NCoR-1 in patients without recurrence have been shown (16-18). In our model we found higher levels of $N C o R-1$ in the MCF-7 $7^{\mathrm{MMU} 1}$ series compared to $\mathrm{MCF}-7^{\mathrm{MMU} 2}$. This could reflect the association of NCoR-1 with ER in the presence of 4-HT in the growth medium of MCF-7MMU1 cells as mRNA was extracted from these cells whilst in the continued presence of 4-HT, and studies have confirmed that NCoR-1 is recruited to the ER in its presence $(53,54)$. In a study using dominant-negative NCoR mutants, Morrison et al (55) demonstrated TAM continued to exert antagonist properties despite loss of co-repressor expression, confirming that NCoR-1 is not solely responsible for the antagonist behaviour of TAM. Therefore, it would seem likely that altered NCoR-1 expression is not independently responsible for driving TAMr, but in association with other factors known to be involved in ER-mediated antagonism (54), may contribute to this transition. Our data would support the notion that alteration of NCoR-1 alone does not mediate TAMr since MCF-7 ${ }^{\mathrm{MMU} 1}$ and MCF-7 ${ }^{\mathrm{MMU} 2}$ cells showed marked differences in $N C o R-1$ expression. Fewer studies have reported on the significance of SMRT in TAMr. Chan et al (56) found no association between SMRT and altered response to TAM in a cohort of TAMr tumours. Fleming et al (47) confirmed the preferential recruitment of this repressor to the ER in the presence of 4-HT. More recently basal expression of SMRT was significantly increased in toremifene-resistant cells (32). Silencing of both NCoR-1 and SMRT expression by siRNA resulted in TAM-stimulated proliferation in MCF-7 cells (57), supporting a role for these co-repressors in the TAMr phenotype.

Our data additionally illustrate the capacity of microarray technology to identify novel genes involved in TAMr as this revealed 131 up-regulated and 156 down-regulated genes associated with the TAMr phenotype. Other microarray 
studies have identified numerous E2-responsive genes in MCF-7 cells $(58,59)$. As anticipated, many of these genes were down-regulated in MCF-7 ${ }^{\mathrm{MMU} 1}$ cells. These included, GREB1, AREG, CXCL12, CA12, WISP2, EP3, LIV-1 and IGFBP5. The most significantly up-regulated gene was $H M G C S 2$ (79-fold increase in MCF-7MMU1 cells). HMGCS2 catalyses the condensation of acetyl-CoA with acetoacetyl-CoA to form HMG-CoA and CoA in mitochondria and is a key control site of ketogenesis in various hormonal and metabolic situations. It has not previously been implicated in breast cancer. The most down-regulated gene was NPYRl which is expressed in breast tumours (60) and in hormone-dependent but not hormone-independent breast cancer cell lines (61). Small peptide antagonists such as those against NPYR1 have been proposed as novel breast cancer therapies, however downregulation of NPYRI in TAMr would indicate these antagonists are unsuitable in patients who relapse on TAM. In accord with other microarray studies, this study generated an enormous amount of data. As a result it is difficult to predict which might be the most important gene(s) associated with the resistant phenotype, particularly as the most significantly up-regulated gene in this study, HMGCS2, has no previous connection with breast cancer. Studies in this area are on-going.

In summary, loss of ER subtype expression does not contribute to TAMr in this in vitro model. However, increases in co-activator levels, in concert with alterations in genes associated with controlling cell proliferation and survival, as indicated by microarray analysis may underlie TAMr as this revealed a number of genes not previously associated with $\mathrm{TAMr}$ or indeed breast cancer, which may provide the opportunity for novel prognostic and therapeutic targets. Our data also suggest that the expression of steroid receptors, their downstream target genes and their associated co-regulators is not uniform during the acquisition of resistance. Overall, our data highlight that TAMr is a very complex and heterogeneous process that is not controlled by a trivial number of genes.

\section{Acknowledgements}

A.T.P. was the recipient of the Mary \& Alice Smith Fellowship. D.S. and M.C. were supported by Yorkshire Cancer Research. V.S. is additionally supported by the Liz Dawn Breast Cancer Appeal and the Breast Cancer Research Action Group and I.P. by the Susan G. Komen Breast Cancer Foundation (POP0600342).

\section{References}

1. Osborne CK: Tamoxifen in the treatment of breast cancer. $\mathrm{N}$ Engl J Med 339: 1609-1618, 1998.

2. Cuzick J, Powles T, Veronesi U, Forbes J, Edwards R, Ashley S and Boyle P: Overview of the main outcomes in breast-cancer prevention trials. Lancet 361: 296-300, 2003.

3. Ali S and Coombes RC: Endocrine-responsive breast cancer and strategies for combating resistance. Nat Rev Cancer 2: 101-112, 2002.

4. Early Breast Cancer Trialists' Collaborative Group: Effects of chemotherapy and hormonal therapy for early breast cancer on recurrence and 15-year survival: an overview of the randomised trials. Lancet 365: 1687-1717, 2005.

5. Speirs V, Carder PJ, Lane S, Dodwell D, Lansdown MRJ and Hanby AM: Oestrogen receptor $B$ : what it means for patients with breast cancer. Lancet Oncol 5: 174-181, 2004 (erratum published in Lancet Oncol 5: 208, 2004).
6. Bardin A, Boulle N, Lazennec G, Vignon F and Pujol P: Loss of ERß expression as a common step in estrogen-dependent tumor progression. Endocr Relat Cancer 11: 537-551, 2004.

7. Horwitz KB, Jackson TA, Bain DL, Richer JK, Takimoto GS and Tung L: Nuclear receptor coactivators and corepressors. Mol Endocrinol 10: 1167-1177, 1996.

8. McKenna NJ, Lanz RB and O'Malley BW: Nuclear receptor coregulators: cellular and molecular biology. Endocr Rev 20: 321-344, 1999.

9. Rosenfeld MG and Glass CK: Coregulator codes of transcriptional regulation by nuclear receptors. J Biol Chem 276: 36865-36868, 2001.

10. Bautista S, Valles H, Walker RL, Anzick S, Zeillinger R, Meltzer $\mathrm{P}$ and Theillet $\mathrm{C}$ : In breast cancer, amplification of the steroid receptor coactivator gene AIB1 is correlated with estrogen and progesterone receptor positivity. Clin Cancer Res 4: 2925-2929, 1998.

11. Murphy LC, Simon SL, Parkes A, et al: Altered expression of estrogen receptor coregulators during human breast tumorigenesis. Cancer Res 60: 6266-6271, 2000.

12. Bouras T, Southey MC and Venter DJ: Overexpression of the steroid receptor coactivator AIB1 in breast cancer correlates with the absence of estrogen and progesterone receptors and positivity for p53 and HER2/neu. Cancer Res 61: 903-907, 2001 .

13. Smith CL, Nawaz Z and O'Malley BW: Coactivator and corepressor regulation of the agonist/antagonist activity of the mixed antiestrogen, 4-hydroxytamoxifen. Mol Endocrinol 11: 657-666, 1997.

14. Xu J, Qiu Y, De Mayo FJ, Tsai SY, Tsai MJ and O'Malley BW: Partial hormone resistance in mice with disruption of the steroid receptor coactivator-1 (SRC-1) gene. Science 279: 1922-1925, 1998.

15. Osborne CK, Bardou V, Hopp TA, et al: Role of the estrogen receptor coactivator AIB1 (SRC-3) and HER-2/neu in tamoxifen resistance in breast cancer. J Natl Cancer Inst 95: 353-361, 2003.

16. Lavinsky RM, Jepsen $\mathrm{K}$, Heinzel $\mathrm{T}$, et al: Diverse signalling pathways modulate nuclear receptor recruitment of $\mathrm{N}-\mathrm{CoR}$ and SMRT complexes. Proc Natl Acad Sci USA 95: 2920-2925, 1998.

17. Kurebayashi J, Otsuki T, Kunisue H, Tanaka K, Yamamoto S and Sonoo H: Expression levels of estrogen receptor- $\alpha$, estrogen receptor- $\beta$, coactivators, and corepressors in breast cancer. Clin Cancer Res 6: 512-518, 2000.

18. Girault I, Lerebours F, Amarir S, et al: Expression analysis of estrogen receptor $\alpha$ coregulators in breast carcinoma: evidence that NCOR1 expression is predictive of the response to tamoxifen. Clin Cancer Res 9: 1259-1266, 2003.

19. Montano MM, Ekena K, Delage-Mourroux R, Chang W, Martini $\mathrm{P}$ and Katzenellenbogen BS: An estrogen receptorselective coregulator that potentiates the effectiveness of antiestrogens and represses the activity of estrogens. Proc Natl Acad Sci USA 96: 6947-7001, 1999.

20. Furr BJ and Jordan VC: The pharmacology and clinical uses of tamoxifen. Pharmacol Ther 25: 127-205, 1984.

21. Stearns V, Johnson MD, Rae JM, et al: Active tamoxifen metabolite plasma concentrations after co-administration of tamoxifen and the selective serotonin reuptake inhibitor paroxetine. J Natl Cancer Inst 95: 1758-1764, 2003.

22. Johnson MD, Zuo H, Lee KH, et al: Pharmacological characterization of 4-hydroxy-N-desmethyl tamoxifen, a novel active metabolite of tamoxifen. Breast Cancer Res Treat 85: 151-159, 2004.

23. Knowlden JM, Hutcheson IR, Jones HE, et al: Elevated levels of epidermal growth factor receptor/c-erbB2 heterodimers mediate an autocrine growth regulatory pathway in tamoxifen-resistant MCF-7 cells. Endocrinology 144: 1032-1044, 2003.

24. Skliris GP, Parkes AT, Limer JL, Burdall SE, Carder PJ and Speirs V: Evaluation of seven oestrogen receptor beta antibodies for immunohistochemistry, western blotting, and flow cytometry in human breast tissue. J Pathol 197: 155-162, 2002.

25. Limer JL, Parkes AT and Speirs V: Differential response to phytoestrogens in endocrine sensitive and resistant breast cancer cells in vitro. Int J Cancer 119: 515-521, 2006.

26. Ponchel F, Toomes C, Bransfield K, et al: Real-time PCR based on SYBR-Green I fluorescence: an alternative to the TaqMan assay for a relative quantification of gene rearrangements, gene amplifications and micro gene deletions. BMC Biotechnol 3: 18-31, 2003. 
27. Brunner N, Frandsen TL, Holst-Hansen C, et al: MCF7/LCC2: a 4-hydroxytamoxifen resistant human breast cancer variant that retains sensitivity to the steroidal antiestrogen ICI 182,780 . Cancer Res 53: 3229-3232, 1993.

28. Badia E, Duchesne M-J, Semlali A, et al: Long-term hydroxytamoxifen treatment of an MCF-7-derived breast cancer cell line irreversibly inhibits the expression of estrogenic genes through chromatin remodeling. Cancer Res 60: 4130-4138, 2000.

29. Herman ME and Katzenellenbogen BS: Response-specific antiestrogen resistance in a newly characterized MCF-7 human breast cancer cell line resulting from long-term exposure to transhydroxytamoxifen. J Steroid Biochem Mol Biol 59: 121-134, 1996.

30. Rabenoelina F, Semlali A, Duchesne MJ, Freiss G, Pons M and Badia E: Effect of prolonged hydroxytamoxifen treatment of MCF-7 cells on mitogen activated kinase cascade. Int J Cancer 98: 698-706, 2002.

31. Hutcheson IR, Knowlden JM, Madden TA, et al: Oestrogen receptor-mediated modulation of the EGFR/MAPK pathway in tamoxifen-resistant MCF-7 cells. Breast Cancer Res Treat 81: 81-93, 2003.

32. Sarvilinna N, Eronen H, Miettinen S, Vienonen A and Ylikomi T: Steroid hormone receptors and coregulators in endocrine-resistant and estrogen-independent breast cancer cells. Int J Cancer 118: 832-840, 2006

33. De Cremoux P, Tran-Perennou C, Brockdorff BL, et al: Validation of real-time RT-PCR for analysis of human breast cancer cell lines resistant or sensitive to treatment with antiestrogens. Endocr Relat Cancer 10: 409-418, 2003.

34. Fasco MJ, Amin A, Pentecost BT, Yang Y and Gierthy JF: Phenotypic changes in MCF-7 cells during prolonged exposure to tamoxifen. Mol Cell Endocrinol 206: 33-47, 2003.

35. Shaw LE, Sadler AJ, Pugazhendhi D and Darbre PD: Changes in oestrogen receptor- $\alpha$ and $-\beta$ during progression to acquired resistance to tamoxifen and fulvestrant (Faslodex, ICI 182,780) in MCF7 human breast cancer cells. J Steroid Biochem Mol Biol 99: 19-32, 2006.

36. Lykkesfeldt A, Madsen M and Briand P: Altered expression of estrogen-regulated genes in a tamoxifen-resistant and ICI 164,384 and ICI 182,780 sensitive human breast cancer cell line, MCF-7/ TAMR-1. Cancer Res 54: 1587-1595, 1994.

37. Bieche I, Parfait B, Laurendeau I, Girault I, Vidaud M and Lidereau R: Quantification of estrogen receptor $\alpha$ and $\beta$ expression in sporadic breast cancer. Oncogene 20: 8109-8115, 2001.

38. Osipo C, Gajdos C, Li H, Chen B and Jordan VC: Paradoxical action of fulvestrant in estradiol-induced regression of tamoxifenstimulated breast cancer. J Natl Cancer Inst 95: 1597-1608, 2003.

39. Jarvinen TAH, Pelto-Huikko M, Holli $\mathrm{K}$ and Isola J: Estrogen receptor $\beta$ is coexpressed with ER $\alpha$ and PR and associated with nodal status, grade and proliferation rate in breast cancer. Am J Pathol 156: 29-35, 2000.

40. Omoto Y, Inoue S, Ogawa S, et al: Clinical value of the wildtype estrogen receptor beta expression in breast cancer. Cancer Lett 163: 207-212, 2001

41. Roger P, Sahla ME, Makela S, Gustafsson JA, Baldet P and Rochefort H: Decreased expression of estrogen receptor $B$ protein in proliferative preinvasive mammary tumors. Cancer Res 61: 2537-2541, 2001.

42. Naundorf H, Becker M, Lykkesfeldt AE, et al: Development and characterization of a tamoxifen-resistant breast carcinoma xenograft. Br J Cancer 82: 1844-1850, 2000.

43. Anzick SL, Kononen J, Walker RL, et al: AIB1, a steroid receptor coactivator amplified in breast and ovarian cancer. Science 277: 965-968, 1997

44. Thenot S, Charpin M, Bonnet S and Cavailles V: Estrogen receptor cofactors expression in breast and endometrial human cancer cells. Mol Cell Endocrinol 156: 85-93, 1999.

45. Vienonen A, Miettinen S, Manninen T, Altucci L, Wilhelm E and Ylikomi T: Regulation of nuclear receptor and cofactor expression in breast cancer cell lines. Eur J Endocrinol 148: 469-479, 2003.
46. Shang Y and Brown M: Molecular determinants for the tissue specificity of SERMs. Science 295: 2465-2468, 2002.

47. Fleming FJ, Hill ADK, McDermott EW, O'Higgins NJ and Young LS: Differential recruitment of coregulator proteins steroid receptor coactivator-1 and silencing mediator for retinoid and thyroid receptors to the estrogen receptor-estrogen response element by $\beta$-estradiol and 4-hydroxytamoxifen in human breast cancer. J Clin Endocrinol Metab 89: 375-383, 2004.

48. Lanz RB, McKenna NJ, Onate SA, et al: A steroid receptor coactivator, SRA, functions as an RNA and is present in an SRC-1 complex. Cell 97: 17-27, 1999.

49. Chooniedass-Kothari S, Hamedani MK, Troup S, Hube F and Leygue E: The steroid receptor RNA activator protein is expressed in breast tumor tissues. Int J Cancer 118: 1054-1059, 2006.

50. Delage-Mourroux R, Martini PGV, Choi I, Kraichely DM, Hoeksema J and Katzenellenbogen BS: Analysis of estrogen receptor interaction with a repressor of estrogen receptor activity (REA) and the regulation of estrogen receptor transcriptional activity by REA. J Biol Chem 275: 35848-35856, 2000.

51. Martini PGV and Katzenellenbogen BS: Modulation of estrogen receptor activity by selective coregulators. J Steroid Biochem Mol Biol 85: 117-122, 2003.

52. Mussi P, Liao L, Park SE, et al: Haploinsufficiency of the corepressor of estrogen receptor activity (REA) enhances estrogen receptor function in the mammary gland. Proc Natl Acad Sci USA 103: 16716-16721, 2006.

53. Kurokawa H, Lenferink AEG, Simpson JF, et al: Inhibition of HER2/neu (erbB-2) and mitogen-activated protein kinases enhances tamoxifen action against HER2-overexpressing, tamoxifen-resistant breast cancer cells. Cancer Res 60: 5887-5894, 2000.

54. Liu XF and Bagchi MK: Recruitment of distinct chromatinmodifying complexes by tamoxifen-complexed estrogen receptor at natural target gene promoters in vivo. J Biol Chem 279: $15050-15058,2004$.

55. Morrison AJ, Herrera RE, Heinsohn EC, Schiff R and Osborne CK: Dominant-negative nuclear receptor corepressor relieves transcriptional inhibition of retinoic acid receptor but does not alter the agonist/antagonist activities of the tamoxifenbound estrogen receptor. Mol Endocrinol 17: 1543-1554, 2003.

56. Chan CM, Lykkesfeldt AE, Parker MG and Dowsett M: Expression of nuclear receptor interacting proteins TIF-1, SUG-1, receptor interacting protein 140, and corepressor SMRT in tamoxifen-resistant breast cancer. Clin Cancer Res 5: 3460-3467, 1999.

57. Keeton EK and Brown M: Cell cycle progression stimulated by tamoxifen-bound estrogen receptor-alpha and promoter-specific effects in breast cancer cells deficient in N-CoR and SMRT. Mol Endocrinol 19: 1543-1554, 2005.

58. Frasor J, Danes JM, Komm B, Chang KC, Lyttle CR and Katzenellenbogen BS: Profiling of estrogen up- and downregulated gene expression in human breast cancer cells: insights into gene networks and pathways underlying estrogenic control of proliferation and cell phenotype. Endocrinology 144: 4562-4574, 2003.

59. Frasor J, Stossi F, Danes JM, Komm B, Lyttle CR and Katzenellenbogen BS: Selective estrogen receptor modulators: discrimination of agonistic versus antagonistic activities by gene expression profiling in breast cancer cells. Cancer Res 64: 1522-1533, 2004.

60. Reubi JC, Gugger M, Waser B and Schaer JC: Y(1)-mediated effect of neuropeptide $\mathrm{Y}$ in cancer: breast carcinomas as targets. Cancer Res 61: 4636-4641, 2001.

61. Kuang WW, Thompson DA, Hoch RV and Weigel RJ: Differential screening and suppression subtractive hybridization identified genes differentially expressed in an estrogen receptorpositive breast carcinoma cell line. Nucleic Acids Res 26: 1116-1123, 1998. 